\title{
自動縫合器を用いた肺悪性腫瘍切除後の肺実質切除断端肉芽腫と断端再発の鑑別
}

\author{
水野潔道 $1 \cdot$ 大出泰久 $1 \cdot$ 林 $\quad$ 祥子 $1 \cdot$ 保浦慶之 $1 \cdot$ 清水麗子 $1 \cdot$ \\ 茅田洋之 1 児嶋秀晃 $1 \cdot$ 高橋祥司 $1 \cdot$ 井坂光宏 1
}

\section{Clinical Differentiations in Stump Granuloma and Stump Recurrence After Lung Resection for Malignancy Using a Stapler}

Kiyomichi Mizuno1; Yasuhisa Ohde1; Shoko Hayashi1; Yoshiyuki Yasuura1; Reiko Shimizu1; Hiroyuki Kayata1; Hideaki Kojima1; Shoji Takahashi1; Mitsuhiro Isaka1

${ }^{1}$ Department of Thoracic Surgery, Shizuoka Cancer Center, Japan.

ABSTRACT - Objective. To identify the clinical differences between stump granuloma and stump recurrence after lung resection for malignancy using a stapler. Methods. We conducted retrospective analyses of 4 patients with stump granulomas and 10 patients with stump recurrences who were pathologically diagnosed at our institution from September 2002 to December 2016. Result. The mean intervals from the previous lung resection to the radiological diagnosis of the lesions (disease-free interval: DFI) were $28.0 \pm 13.5$ months for granulomas and $19.1 \pm 13.4$ months for stump recurrences. The maximum standardized uptake values (SUV) by ${ }^{18} \mathrm{~F}$ fluorodeoxyglucose positron emission tomography (FDG PET) were $4.8 \pm 2.9$ for granulomas and $7.5 \pm 3.6$ for stump recurrences. The preoperative carcinoembryonic antigen (CEA) levels were $2.5 \pm 0.7 \mathrm{ng} / \mathrm{dl}$ for granulomas and $12.2 \pm 25.3 \mathrm{ng} / \mathrm{dl}$ for stump recurrences. However, there were no significant differences in the clinical characteristics between granulomas and recurrences. CEA levels were within normal limits in all granuloma cases, and in all recurrence cases, the SUVmax was $>2$. The staple lines of the previous resection were present in the peripheral areas of the new masses in all granuloma cases but only seen in about half of the stump recurrence cases. Conclusions. For patients with a short DFI, high SUVmax and CEA levels, and staple lines located in the middle, stump recurrence should be suspected, and a pathological diagnosis should be made, such as via a percutaneous biopsy.

KEY WORDS — Granuloma, Stump recurrence, Staple line

(JJLC. 2017;57:826-831)

Corresponding author: Kiyomichi Mizuno.

Received June 19, 2017; accepted October 12, 2017.

要旨一一目的. ステープラーによる肺実質切離を行っ た悪性腫瘍術後の断端肉芽腫と断端再発の臨床的鑑別点 を明らかにする. 方法. 当院において 2002 年 9 月から 2016 年 12 月までに病理診断を得た断端肉芽腫 4 例, 断 端再発 10 例を比較検討した. 結果. 手術から腫瘤出現 までの期間 (DFI) は断端肉芽腫では平均值 $28.0 \pm 13.5$ ケ 月，断端再発では $19.1 \pm 13.4$ ケ月であった. SUVmax は平均值 $4.8 \pm 2.9$ と $7.5 \pm 3.6$, 術前 CEA はそれぞれ 2.5 $\pm 0.7 \mathrm{ng} / \mathrm{dl}$ と $12.2 \pm 25.3 \mathrm{ng} / \mathrm{dl}$ であり, いずれも統計学 的に有意差を認めなかった. 肉芽腫では全例において
CEA は $5 \mathrm{ng} / \mathrm{dl}$ 未満で, 断端再発では全例が SUVmax が 2 以上であった。 また, 肉芽腫では全例肺切除時のス テープルラインが腫瘤の辺縁に位置していたが，再発例 では 10 例中 4 例で腫瘤の中央に位置していた。結論。 DFI が短い, PET の FDG 集積が高い, CEA が高值, ス テープルラインが腫瘤の中心に存在する場合は断端再発 をより疑い, 経皮生検など, 積極的に病理学的診断をつ けることが望ましい.

索引用語——肉芽腫, 断端再発, ステープルライン 


\section{はじめに}

肺切除後, ステープラーによる肺切離端に肉芽腫が形 成されることがある。1-11 特に, 悪性腫瘍手術後では肉芽 腫か断端再発かの鑑別がしばしば問題となる。今回，病 理診断を得た症例を比較し，両者の鑑別点について検討 した。

\section{対象と方法}

当院において 2002 年 9 月から 2016 年 12 月までに 行った肺悪性腫瘍に対する肺切除症例のうち, 病理組織 診断の得られた肺切除断端肉芽腫と断端再発を臨床的に 比較検討した. 手術後, 半年毎の造影 CT 検査を行い, 放 射線診断医に断端腫瘤形成を初めて指摘された時点を腫 瘤出現の起算日とした. $2 \sim 3$ ヶ月後のフォロー CT で増 大傾向を認めるか, ${ }^{18}$ F-fluorodeoxyglucose (FDG) PETCT で異常集積を認めた場合には，手術または CT ガイ ド下生検にて病理組織診断を得た。腫瘍倍加時間 tumor doubling time（TDT）は， 1 ケ月以上の期間を空けた 2 点の腫瘍径を Schwartzの式より算出した.

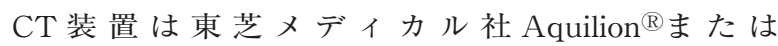
Aquilion ONE ${ }^{\mathrm{TM}}$ で, 造影条件は非イオン性造影剤を末梢 静脈からボーラス注入し, 静脈相 (90 秒後) で CT 值を
評価した. CT 值は FUJIFILM SYNAPSE ${ }^{\circledR}$ 用いて，ス テープルを含まないように腫瘤の内部を取り囲んで測定 し, その平均值とした。

2 群間の比較には母集団の分散によって Student- $\mathrm{t}$ 検 定または Welch 検定を用い， $P<0.05$ を統計学的に有意 とした。

\section{結 果}

断端肉芽腫は 4 例, 断端再発は 10 例であった. 患者背 景（Table 1) は断端肉芽腫では男性 1 例, 女性 3 例で, 断端再発例では男性 6 例, 女性 4 例であった。肉芽腫の 原疾患は, 原発性肺癌が 3 例, 大腸癌肺転移が 1 例であっ た. 肉芽腫の病理組織診断の方法は残肺葉切除が 1 例, 残りの 3 例は CT下生検であった。 CT下生検時の組織 から抗酸菌培養を行ったところ 1 例でMycobacterium avium が陽性となった. 断端再発の診断は全例, 外科切除 による病理診断であった。初回手術の術式は, 肉芽腫で は全例で区域切除，断端再発では部分切除 9 例と肺葉切 除 +区域切除 1 例であった。 CT 画像の一覧を Figure 1 に示す.

手術から肺実質切除断端に結節が出現するまでの期間 disease-free interval（DFI）は肉芽腫で平均值 $28.0 \pm$ 13.5 ケ月，再発で $19.1 \pm 13.4$ ケ月であり，TDTはそれぞ

Table 1. Patient Characteristics

\begin{tabular}{|c|c|c|c|c|c|c|c|c|c|c|c|c|c|}
\hline \multicolumn{14}{|c|}{ Granuloma cases } \\
\hline & & $\begin{array}{c}\text { Age } \\
\text { (years) }\end{array}$ & $\begin{array}{c}\text { Gen- } \\
\text { der }\end{array}$ & $\begin{array}{l}\text { - Primary } \\
\text { diagnosi }\end{array}$ & $\begin{array}{l}\text { Surgical } \\
\text { procedure }\end{array}$ & $\begin{array}{c}\text { DFI } \\
\text { (months) }\end{array}$ & $\begin{array}{l}\text { TDT C } \\
\text { (days) (ng }\end{array}$ & $\begin{array}{l}\text { CEA Siz } \\
\mathrm{g} / \mathrm{dl})(\mathrm{cn}\end{array}$ & $\begin{array}{ll}\text { ize } & P 1 \\
\text { m) } & \text { (St }\end{array}$ & $\begin{array}{l}\text { PET-CT E } \\
\text { SUVmax) }\end{array}$ & $\begin{array}{c}\text { Enhance- } \\
\text { ment } \\
\text { (HU) }\end{array}$ & $\begin{array}{c}\text { Position } \\
\text { with mass } \\
\text { and staple }\end{array}$ & $\begin{array}{l}\text { Diagnostic } \\
\text { approach }\end{array}$ \\
\hline \multirow[t]{6}{*}{ Granulomas } & Case 1 & 43 & $\mathrm{~F}$ & CRCPM & $\mathrm{S}^{6}$ segmentectomy & 15 & 16 & 2.1 & 1.7 & 6.0 & 45.74 & peripheral & surgery \\
\hline & Case 2 & 72 & M & LC & $\mathrm{S}^{2}$ segmentectomy & 26 & 355 & 3.3 & 2.4 & 1.5 & 61.23 & peripheral & CTNB \\
\hline & Case 3 & 72 & $\mathrm{~F}$ & $\mathrm{LC}$ & $\mathrm{S}^{2}$ segmentectomy & 47 & 384 & 2.0 & 4.1 & 7.0 & 63.89 & peripheral & CTNB \\
\hline & Case 4 & 73 & $\mathrm{~F}$ & $\mathrm{LC}$ & $\mathrm{S}^{2}$ segmentectomy & 24 & 120 & - & 4.7 & - & 85.01 & peripheral & CTNB \\
\hline & \multicolumn{13}{|c|}{ Recurrent cases } \\
\hline & & $\begin{array}{c}\text { Age } \\
\text { (years) }\end{array}$ & $\begin{array}{l}\text { Gen- } \\
\text { der }\end{array}$ & $\begin{array}{l}\text { Primary } \\
\text { diagnosis }\end{array}$ & Surgical procedure & $\begin{array}{c}\text { DFI } \\
\text { (months) }\end{array}$ & $\begin{array}{c}\text { TDT } \\
\text { s) (days) }\end{array}$ & $\begin{array}{c}\text { CEA } \\
(\mathrm{ng} / \mathrm{dl})\end{array}$ & $\begin{array}{l}\text { Size } \\
(\mathrm{cm})\end{array}$ & $\begin{array}{l}\text { PET-CT } \\
\text { (SUVmax) }\end{array}$ & $\begin{array}{l}\text { Enhance- } \\
\text { x) } \\
\text { ment } \\
(\mathrm{HU})\end{array}$ & $\begin{array}{l}\text { Position } \\
\text { with mass } \\
\text { and staple }\end{array}$ & $\begin{array}{l}\text { Diagnostic } \\
\text { approach }\end{array}$ \\
\hline \multirow{10}{*}{ Recurrence } & Case 1 & 84 & M I & LC & $\mathrm{S}^{10}$ wedge resection & 2 & 412 & 2.2 & 3.3 & 5.8 & 87.78 & central & CTNB \\
\hline & Case 2 & 75 & F I & LC & $\mathrm{S}^{3}$ wedge resection & 19 & 91 & 1.8 & 1.4 & 5.1 & 75.79 & central & surgery \\
\hline & Case 3 & 82 & M & CRCPM S & $\mathrm{S}^{5}$ wedge resection & 36 & 45 & 5.7 & 1.5 & 11.9 & 66.84 & peripheral & surgery \\
\hline & Case 4 & 75 & $\mathrm{~F}$ & $\mathrm{LC} \quad \mathrm{S}$ & $\mathrm{S}^{2}$ wedge resection & 8 & 56 & 3.5 & 1.8 & 14.0 & 91.23 & peripheral & surgery \\
\hline & Case 5 & 64 & $\mathrm{M}$ & LC $\quad \mathrm{H}$ & $\mathrm{RML}+\mathrm{S}^{7}$ segmentectomy & 24 & - & 2.8 & 1.5 & 11.2 & 85.93 & central & surgery \\
\hline & Case 6 & 55 & $\mathrm{~F}$ & CRCPM S & $\mathrm{S}^{4}, \mathrm{~S}^{9}$ wedge resection & 8 & 59 & 83.8 & 3.1 & 7.5 & 87.23 & peripheral & surgery \\
\hline & Case 7 & 53 & $\mathrm{~F}$ & LC $\quad S$ & $\mathrm{~S}^{4}$ wedge resection & 14 & 120 & 1.2 & 2.2 & 4.5 & 80.36 & peripheral & surgery \\
\hline & Case 8 & 60 & $\mathrm{M}$ & $\mathrm{LC} \quad \mathrm{S}$ & $\mathrm{S}^{1}$ wedge resection & 24 & - & 5.4 & 1.0 & 2.3 & 63.69 & peripheral & surgery \\
\hline & Case 9 & 77 & $\mathrm{M}$ & CRCPM S & $\mathrm{S}^{4}$ wedge resection & 45 & - & 12.3 & 4.8 & 6.8 & 73.52 & central & surgery \\
\hline & Case 10 & 76 & $\mathrm{M}$ & CRCPM S & $\mathrm{S}^{10}$ wedge resection & 11 & - & 3.1 & 1.1 & 3.8 & 64.15 & peripheral & surgery \\
\hline
\end{tabular}

LC, lung cancer; CRCPM, colorectal cancer pulmonary metastasis; DFI, disease-free interval; TDT, tumor doubling time; CEA, carcinoembryonic antigen; SUV, standardized uptake value; CTNB, CT-guided needle biopsy. 

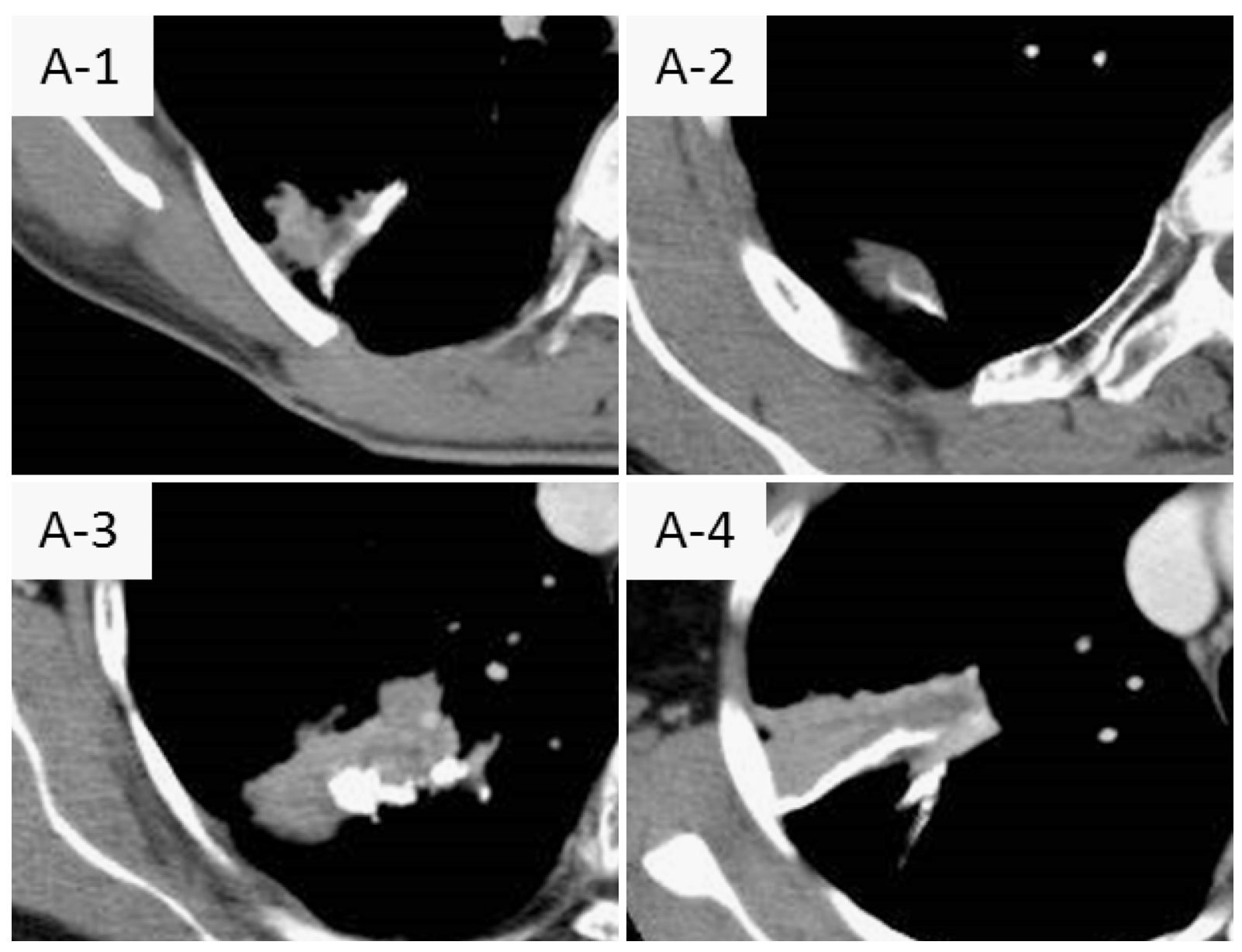

Figure 1. Stump granulomas. Chest computed tomography (CT) showed a new mass near the staple line. (A-1) Case 1: 15 months after $\mathrm{S}^{6}$ segmentectomy. (A-2) Case 2: 26 months after $\mathrm{S}^{2}$ segmentectomy. (A-3) Case 3: 47 months after $\mathrm{S}^{2}$ segmentectomy. (A-4) Case 4: 24 months after $\mathrm{S}^{2}$ segmentectomy. The staple lines were present at the margins of the masses in all 4 patients.

Table 2. Nodule Characteristics

\begin{tabular}{lccc}
\hline Characteristic & $\begin{array}{c}\text { Granuloma } \\
(\mathrm{n}=4)\end{array}$ & $\begin{array}{c}\text { Recurrence } \\
(\mathrm{n}=10)\end{array}$ & $P$ value \\
\hline $\begin{array}{l}\mathrm{DFI} \\
\text { mean } \pm \mathrm{SD}\end{array}$ & $28.0 \pm 13.5$ & $19.1 \pm 13.4$ & $0.286^{*}$ \\
$\begin{array}{l}\mathrm{TDT} \\
\text { mean } \pm \mathrm{SD}\end{array}$ & $218.7 \pm 179.5$ & $130.5 \pm 140.6$ & $0.407^{*}$ \\
$\begin{array}{l}\mathrm{SUVmax} \\
\text { mean } \pm \mathrm{SD}\end{array}$ & $4.8 \pm 2.9$ & $7.5 \pm 3.6$ & $0.272^{*}$ \\
$\begin{array}{l}\text { Enhancement } \\
\text { mean } \pm \mathrm{SD}\end{array}$ & $63.9 \pm 16.2$ & $77.6 \pm 10.3$ & $0.191^{\dagger}$ \\
$\begin{array}{l}\text { CEA } \\
\text { mean } \pm \mathrm{SD}\end{array}$ & $2.5 \pm 0.7$ & $12.2 \pm 25.3$ & $0.257^{\dagger}$ \\
\hline
\end{tabular}

DFI, disease-free interval; TDT, tumor doubling time; SUVmax, standardized uptake value; CEA, carcinoembryonic antigen; SD, standard deviation.

*Student-t test; ${ }^{\dagger}$ Welch test.
れ平均值 $218.7 \pm 179.5$ 日と $130.5 \pm 140.6$ 日, FDG PETCT では standardized uptake value 最大值 (SUVmax) は 平均值 $4.8 \pm 2.9$ と $7.5 \pm 3.6$ であった。

結節の造影効果の CT 值はそれぞれ平均值 $63.9 \pm 16.2$ $\mathrm{HU}$ と $77.6 \pm 10.3 \mathrm{HU}$, 術前 $\mathrm{CEA}$ は $2.5 \pm 0.7 \mathrm{ng} / \mathrm{dl}$ と 12.2 $\pm 25.3 \mathrm{ng} / \mathrm{dl}$ であり, いずれも統計学的に有意差を認め なかった（Table 2).

また, 肉芽腫は全例で CEA が $5 \mathrm{ng} / \mathrm{dl}$ 未満, 断端再発 では 4 例が CEAの上昇を認めた。断端再発では全例で SUVmax 2 を超えていた.

ステープルラインと腫瘍の位置関係を比較すると, 肉 芽腫では全例, 肺切離時のステープルラインが腫瘤の辺 縁に位置したが, 再発例では 6 例が辺縁で, 残り 4 例で は腫瘤に巻き込まれる形で存在していた（Figure 2).

\section{考 察}

ステープラーは肺実質を解剖学的または非解剖学的に 


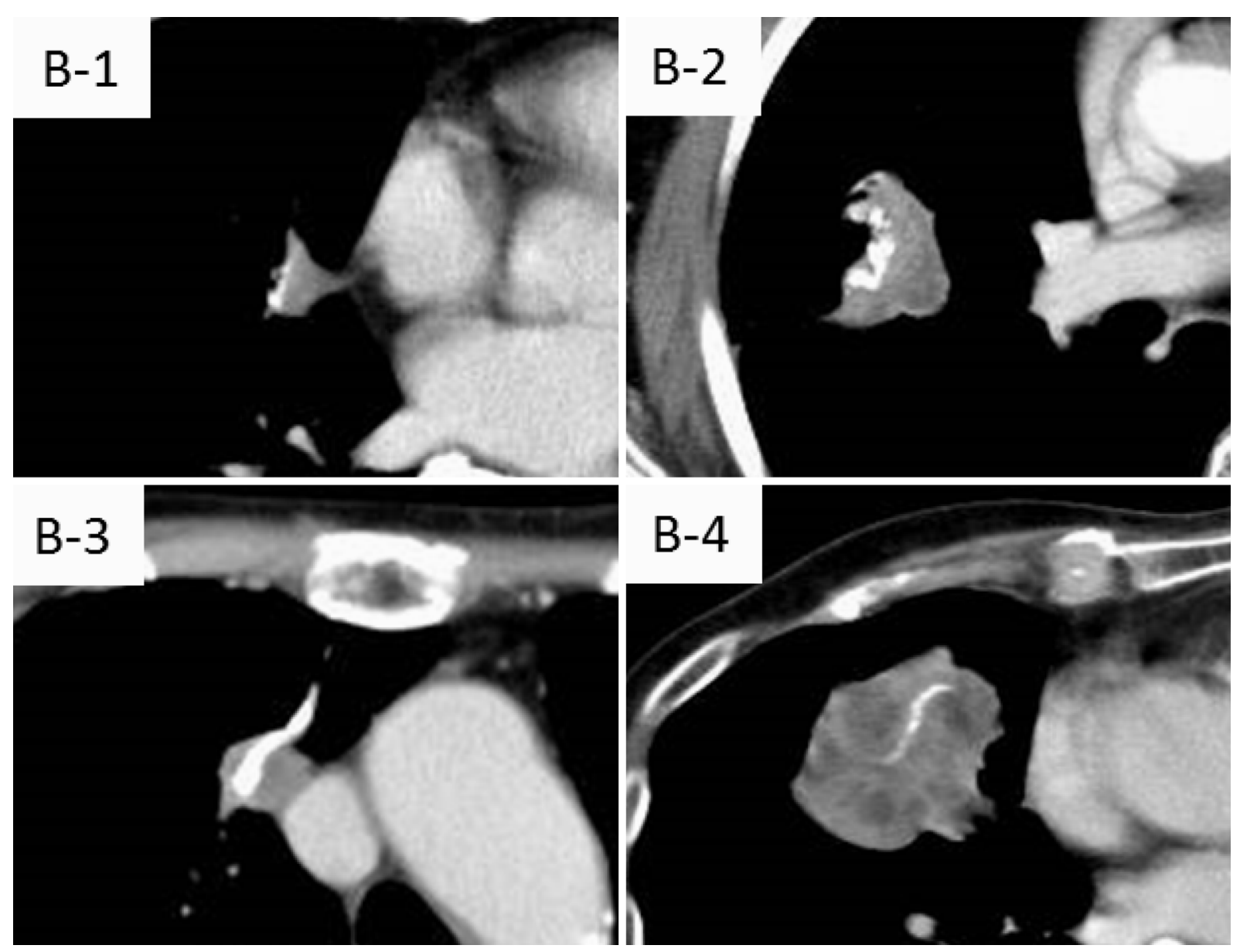

Figure 2. Stump recurrence. The staple lines of Cases 3 (B-1) and 6 (B-2) were present in the peripheral areas of the masses. The staple lines of Cases 2 (B-3) and 9 (B-4) were present in the center of the masses.

切離する際に有用であり，近年使用頻度は増えている. しかし，それに伴う合併症も報告されており，肺切除断 端に形成される肉芽腫もその 1 つである。

切除断端に生じる増殖性疾患の鑑別としてステープル や縫合糸に対する異物性肉芽腫, 1,4,6,7,9,11-13 結核菌や非結 核性抗酸菌症の感染による抗酸菌性肉芽腫, $2,3,5,8,10$ 肺梗 塞・肺壊死, 14 断端再発などが生じうる. 肉芽腫は抗原 提示によりマクロファージが活性化し異物を中心に類上 皮細胞が形成される反応である。しかし，悪性腫瘍手術 後においては断端再発との鑑別が臨床上, 重要な問題と なる。これまで画像上の鑑別点として肉芽腫では辺縁の 形態, 石灰化の有無, 血管・気管支の関与の有無などが 報告されているが, $1,2,15$ 決定的な鑑別因子はない.

Table 3 にステープラー使用後の肺実質断端肉芽腫に 関するこれまでの報告をまとめた。切除断端肉芽腫は術 後 5 年以上の比較的晚期に発生している報告があ り, 1,5,7,9 今回の検討でも DFI を断端再発例と比較した が, 2 群間に統計学的な有意差は認められなかった.しか
し原発性肺癌の術後に限ってみると, 断端肉芽腫は 3 例 とも術後 2 年以上経過してから, 断端再発は 6 例とも術 後 2 年以内に発生しており, 断端肉芽腫の発生は断端再 発よりも比較的晚期に起こる可能性が示唆される. 今回 の我々のデータでは症例数も少なく, 統計学的な有意差 を認めなかったが, 術後 2 年以降に出現している報告が 多くあり, 1-3,5,7-10,13 DFI は切除断端肉芽腫と再発との鑑 別点になりうると考えられる。

PET-CT は $10 \mathrm{~mm}$ 以上の肺結節における良悪性の鑑 別に有用であり, 感度が $96 \%$, 特異度が $79 \%$ と報告され ている. 16 FDG は炎症性疾患や抗酸菌感染症, サルコイ ドーシスなどの肉芽腫性疾患でも集積するため, 今回の 検討でも肉芽腫症例で高集積を示す症例があった。した がって, FDGの高集積は必ずしも断端再発とは限らない が, 再発例では全例 SUVmax が 2 以上であり, FDGの集 積がない場合には肉芽腫の可能性が高いと言える.

鎌田らは断端肉芽腫と断端再発の画像的鑑別点として 腫瘤とステープルラインの位置関係に着目している. ${ }^{1}$ 
Table 3. A Summary of Previously Reported Stump Granulomas Treated with Automatic Sutures

\begin{tabular}{|c|c|c|c|c|c|c|c|c|}
\hline Author, year & Disease & Surgical procedure & Location & $\begin{array}{l}\text { Position with } \\
\text { mass and staple }\end{array}$ & $\begin{array}{l}\text { Size } \\
(\mathrm{cm})\end{array}$ & $\begin{array}{c}\text { DFI } \\
\text { (month) }\end{array}$ & $\begin{array}{l}\text { PET-CT } \\
\text { (SUVmax) }\end{array}$ & $\begin{array}{c}\text { CEA } \\
\text { (ng/dl) }\end{array}$ \\
\hline Tomita M, 2003 & PM & wedge resection & Lt upper lobe & peripheral & NR & 17 & NR & WNL \\
\hline Tanaka H, 2003 & $\mathrm{LC}$ & segmentectomy & Lt $\mathrm{S}^{1+2+3}$ & peripheral & 2 & 60 & NR & NR \\
\hline Kono Y, 2005 & $\mathrm{LC}$ & segmentectomy & Lt $\mathrm{S}^{6}$ & unknown & 5 & 24 & NR & 3.7 \\
\hline Furukawa M, 2007 & $\mathrm{LC}$ & segmentectomy & Lt $\mathrm{S}^{3}$ & peripheral & 5 & 48 & NR & WNL \\
\hline Yüksel M, 2007 & $\mathrm{PM}$ & wedge resection & Rt middle lobe & unknown & NR & 4 & 3.5 & NR \\
\hline Otsuka H, 2008 & $\mathrm{PM}$ & wedge resection & Lt $\mathrm{S}^{3}$ & peripheral & 3 & 48 & NR & WNL \\
\hline Eguchi T, 2008 & aspergilloma & wedge resection & Rt S1, $\mathrm{S}^{2}$ & unknown & 4 & 30 & NR & NR \\
\hline Murakami S, 2009 & $\mathrm{LC}$ & lobectomy & Rt middle lobe & peripheral & 2.3 & 86 & 4.59 & 2.5 \\
\hline Motono N, 2012 & PM & wedge resection & Lt $\mathrm{S}^{10}$ & peripheral & NR & 7 & NR & 3.3 \\
\hline Tempaku H, 2012 & $\mathrm{PM}$ & wedge resection & Rt $\mathrm{S}^{10}$ & peripheral & 2.5 & 60 & 1.9 & 2.1 \\
\hline \multirow{2}{*}{ Kamata T, 2015} & PM & wedge resection & Lt $\mathrm{S}^{1+2}$ & \multirow{2}{*}{ peripheral } & 2.5 & 144 & 4.9 & \multirow{2}{*}{ NR } \\
\hline & $\mathrm{LC}$ & segmentectomy & Rt $S^{6}$ & & 3.5 & 36 & 4.0 & \\
\hline \multirow[t]{2}{*}{ This Study, 2016} & PM & segmentectomy (4) & Rt $S^{6}(1)$ & \multirow[t]{2}{*}{ peripheral (4) } & 1.7, 2.4, & 15,26 , & $6.0,1.5$, & 2.1, 3.3, \\
\hline & LC (3) & & Rt S ${ }^{2}(3)$ & & $4.1,4.7$ & 47,26 & $7.0,-$ & $2.0,-$ \\
\hline
\end{tabular}

LC, lung cancer; PM, pulmonary metastasis; DFI, disease-free interval; TDT, tumor doubling time; CEA, carcinoembryonic antigen; SUV, standardized uptake value; NR, not reported; WNL, within normal limits.

肉芽腫において腫瘤はステープルを基部とした三角形状 の形態, すなわちステープルラインが腫瘤の辺縁に位置 しており，断端再発例ではステープルを中心として，そ れを取り囲むように腫瘤を形成する．当院の肉芽腫症例 では, 全例ステープルラインが腫瘤の辺縁に位置してお り，既報告と同様の所見を認めたが，断端再発例におい ても同様にステープルラインが腫瘤の辺縁に位置する症 例が約半数あり, 決定的な鑑別点とはなり得なかった. しかし, 逆にステープルラインが腫瘤に取り囲まれて存 在するときには断端再発である可能性が高いとも言え る. 今回の我々のデータでは, 断端再発例においてステー プルラインが腫瘤の辺縁に存在する症例では, ほとんど が $2 \mathrm{~cm}$ 以下の小型であり, 増大に伴い, 今後ステープル ラインが巻き込まれる可能性がある。したがって, 腫瘤 径が $3 \mathrm{~cm}$ を超えてもステープルラインが腫瘤の辺縁に 存在するケースでは断端肉芽腫が, 逆に $2 \mathrm{~cm}$ 以下の小 型でもステープルラインが中に巻き込まれているケース では断端再発の可能性が高いと推測される.

また, Stephen らは肺結節の良悪性の鑑別に造影 CT において結節の造影効果が 15 HU 以下を示す場合は良 性疾患である可能性が高いと報告している.17 断端腫瘤 の鑑別においても同様に比較したところ, 肉芽腫症例で は断端再発症例に比べて CT 值はやや低い傾向を認めた が統計学的有意差は認められなかった。

\section{結 語}

断端肉芽腫と断端再発の鑑別においてDFIが短い, PET の集積が高い, CEA が高值, ステープルラインが腫 瘤の中心に存在する場合は断端再発をより疑い, 経皮生
検など, 病理学的な診断をつけることが望ましい.

本論文内容に関連する著者の利益相反：なし

本論文の要旨は第 57 回日本肺癌学会学術集会にて発表し た.

\section{REFERENCES}

1. 鎌田嗣正, 渡辺俊一, 櫻井裕幸, 中川加寿夫. 肺実質切除 断端肺癌再発との鑑別を要した肺肉芽腫の 2 例. 日呼外 会誌. 2015;29:700-705.

2. 大塚英男, 神崎正人, 吉川拓磨, 小原徹也, 石澤 貢. 切 除断端再発を疑った肺肉芽腫の 1 例. 日本胸部臨床. 2008;67:977-980.

3. 古川公之, 池田宏国, 竹尾正彦, 山本満雄. 肺癌術後のス テープルラインに発生した非定型抗酸菌症を伴う肺肉芽 腫の 1 例. 日呼外会誌. 2007;21:942-945.

4. 本野 望, 岡田 英, 富樫賢一. 腎細胞癌肺転移切除断端 に発生した肺異物肉芽腫の 1 例. 肺癌. 2012;52:23-26.

5. 村上修司, 斉藤春洋, 坪井正博, 中山治彦, 亀田陽一, 山 田耕三. 肺腺癌術後 8 年目にステープル近傍の切離断端 に発生した抗酸菌性肉芽腫の 1 例. 肺癌. 2009;49:10381042.

6. Tomita M, Matsuzaki Y, Edagawa M, Shimizu T, Hara M, Onitsuka T. Pulmonary granuloma possibly caused by staples after video-assisted thoracoscopic surgery. Ann Thorac Cardiovasc Surg. 2003;9:123-125.

7. 田中壽一, 井内敬二, 松村晃秀, 奥村明之進, 田村光信, 後藤正志, 他. 肺癌左上大区域切除後, 切除断端に発生し た肺結核の 1 例. 日呼外会誌. 2003;17:794-797.

8. 江口 隆, 蔵井 誠, 加藤響子, 富永義明, 小林宣隆, 椎 名隆之, 他. 肺アスペルギローマ術後切除断端に発症した 非結核性抗酸菌症の 1 例. 日呼外会誌. 2008;22:35-38.

9. 天白宏典, 高尾仁二, 鈴木仁之, 島本 亮, 新保秀人. 転 移性肺癌術後 5 年目にステープルラインに発生した異物 
肉芽腫の 1 例。 日呼外会誌. 2012;26:52-55.

10．巷野佳彦，遠藤俊輔，大谷真一，齊藤紀子，長谷川剛，佐 藤幸夫, 他. 区域切除後のステープラー切除端に発症した 非定型抗酸菌症の 1 例. 胸部外科. 2005;58:165-168.

11. Yüksel M, Akgül AG, Evman S, Batirel HF. Suture and stapler granulomas: a word of caution. Eur J Cardiothorac Surg. 2007;31:563-565.

12. Fink G, Herskovitz P, Nili M, Hadar H, Rothem A Spitzer SA. Suture granuloma simulating lung neoplasm occurring after segmentectomy. Thorax. 1993;48:405-406.

13. 桂 浩, 井内敬二, 松村晃秀. Aspergillus 感染を伴っ た肺癌部分切除後の肺縫合糸肉芽腫の 1 例. 胸部外科. 2005;58:169-171.
14. Grismer JT, Schaefer RF, Read RC. Postsegmentectomy pseudotumor of the lung. Ann Thorac Surg. 1998;65:243245.

15. 斉藤春洋. 胸部 CT による肺腫瘤の質的診断. 肺癌. 2008; 48:302-311.

16. Fischer BM, Mortensen J, Højgaard L. Positron emission tomography in the diagnosis and staging of lung cancer: a systematic, quantitative review. Lancet Oncol. 2001;2: 659-666.

17. Swensen SJ, Viggiano RW, Midthun DE, Müller NL, Sherrick A, Yamashita K, et al. Lung nodule enhancement at CT: multicenter study. Radiology. 2000;214:73-80. 